\title{
Cognitive performance during successive sustained physical work episodes
}

\author{
CARL E. ENGLUND, DAVID H. RYMAN, PAUL NAITOH, and JAMES A. HODGDON \\ Naval Health Research Center, San Diego, California
}

\begin{abstract}
The effects of physical work ( $30 \%$ of $\mathrm{VO}_{2}$ max), sleep loss (3-h nap during a 48-h operation), continuous work (CW), and time of day on cognitive performance were assessed (by ANOVA) in this repeated-measures study comparing two groups (exercise/nonexercise) of healthy young men $(\mathrm{N}=22)$. Treadmill walking did not accentuate or attenuate sleep-loss effects on performance; however, sleep loss alone did degrade visual vigilance and memory for words. Time-of-day fluctuations were found in choice reaction time, logical reasoning, and word memory. Visual vigilance for nonexercising subjects degraded sooner on the 2 nd $\mathrm{CW}$ day than it did for exercising subjects. A 3-h nap at $0400 \mathrm{~h}$ after $117-\mathrm{h} \mathrm{CW}$ day was not immediately recuperative. These findings indicate that exercise at $30 \%$ of $\mathrm{VO}_{2}$ max does not compound sleep-loss effects in cognitive performance. Indeed, physical activity during video terminal monitoring may delay any sleep-loss decrement. Variability of many cognitive abilities throughout the day appeared to show a greater effect than the sleep-loss and exercise effects over 2 days.
\end{abstract}

A modern high-technology society requires full-time, round-the-clock services. The usual response to this requirement has taken the form of various shift systems, staffed typically by two or three stationary or rotated crews ("shifts"). However, some occupations require extended periods of continuous work $(\mathrm{CW})$ on a regular or periodic basis. Examples include fire fighters, police, health care providers, rail and air transportation workers, and nuclear, petrochemical, and steel workers. Some of the most dramatic examples of $\mathrm{CW}$ are in military engagements. Military planners recognize that, should engagements be necessary, the weakest link may well be human, not hardware (Radomski \& Defayolle, 1981).

The major endogenous factors delimiting optimum, extended human performance have been identified as health, physical fitness, fatigue, training/skill level, information processing ability, and biological rhythms. External factors are work load, work-rest cycles, and environmental hazards (Englund, 1979; Englund, Naitoh, Ryman, \& Hodgdon, 1983). Resolution of problems arising from the influence of these factors is the subject of intensive investigation. Intervention methods for performance enhancement range from pharmacology (exter-

The work reported here was accomplished by the Naval Medical Research and Development Command under Work Unit MF58.528.01B0003 and reported as NHRC Technical Report No. 84-31. The views presented in this paper are those of the authors. No endorsement by the Department of the Navy has been given or should be inferred. The authors gratefully acknowledge the assistance of members of the First Marine Reconnaissance Battalion of Camp Pendleton, CA, who were subjects in this study. We would also like to thank Louise Jarrett for her editorial assistance in preparing this manuscript. The authors' mailing address is: Environmental Physiology Department, Naval Health Research Center, P.O. Box 85122, San Diego, CA 92138-9174. nal input; see Spinweber \& Johnson, 1983) to sleep management (internal control; see Naitoh, Englund, \& Ryman, 1983). Discovery of the means/mechanisms to support sustained quality mental and physical performance is the major objective of most $\mathrm{CW}$ studies that involve critical industrial or military applications. The relationships between physical work, sleep loss, and mental efficiency are not fully understood and require study, if we are to optimize performance under $\mathrm{CW}$ conditions.

The present study is concerned with mental effectiveness during repeated $\mathrm{CW}$ periods. Successive sustained operations are those in which partial or complete rest/recovery periods separate two or more intensive, extended, work phases. Specifically, we have been studying the effects of continuous and repeated work episodes on cognitive performance, by manipulating the time and length of naps, exercise levels, and time schedules. The prime purpose has been to determine the effectiveness of cognitive performance over lengthy $\mathrm{CW}$ episodes.

\section{METHOD}

\section{Subjects}

Volunteer Marine reconnaissance personnel were obtained from Camp Pendleton, California, and studied in pairs, over a 5-day period. All subjects were young, physically fit males (ages 18-24 years, mean age $=20.5 \pm 1.7$ years, mean $\mathrm{VO}_{2} \max =53.5 \pm 5.9$ ) and were accustomed to sleep loss. All of these subjects were in either a first or a second enlistment; most had completed high school, and the mean Nelson-Denny Reading Test (Brown, 1966) grade level was $11.2(\mathrm{SD}=2.4)$. The nature of the study and the risks involved were explained verbally and given in written form to all of the subjects prior to their voluntary consent to participate. All had the right to withdraw 
from the study. They could also be withdrawn if the attending medical officer and experiments found them unable to continue.

\section{Materials}

The study was conducted at the Physical Fitness and Ergonomics Laboratories of the U.S. Naval Health Research Center (NHRC), San Diego, California. Within the Ergonomics Lab are a sound-reduced, electronically shielded sleep room and an air-conditioned exercise room. Equipment used included a DEC MINC 11 computer with VT 105 and VT 100 video terminals, a Tektronix 4051 computer, and a Quinton Model 18-60 clinical research treadmill. Other equipment included a polygraph, FM instrumentation tape recorder, four electronic filters, and four differential amplifiers.

\section{Measurements}

Physical work was a major independent variable presented in two levels: moderate physical workload versus no physical workload, selected to test for effects on cognitive performance. Additionally, a 3-h nap was allowed midway (0400-0700 h) between sustained episodes to determine the restorative effects of the nap at that particular time of day. Oral temperatures, blood pressures, grip strengths, heart rates, and sleep polygraphs were systematically measured on all subjects. The results on these measurements have been presented elsewhere (Englund et al., 1983; Naitoh, Englund, \& Ryman, 1982). A description of the computerized portion of the NHRC Performance Assessment Battery (PAB) utilized in the sustained operations (SUSOPS) series of studies at the lab was provided in Ryman, Naitoh, and Englund (1984) (see also Naitoh, 1981, and Naitoh et al., 1982, 1983). The other independent variables were sustained work and sleep loss. The sustained work episodes consisted of 17 sets of two .5-h segments each day: Visual vigilance with physical work was given the first $.5 \mathrm{~h}$, and computer-generated tasks and other performance measures the second $.5 \mathrm{~h}$. The protocol (Figure 1) and treatment sequences are detailed in the Procedure section below. The dependent measures and focus of this paper are described in the Description of Tasks section.

\section{Description of Tasks}

Air Defense Game. This task, representing significant features of a Navy tactical problem, was developed at the Navy Personnel Research and Development Center, San Diego. Details of the computer simulation and game scenario may be found in Greitzer, Hershman, and Kelly (1981). This task utilizes a Tektronix 4051 microcomputer and simulates a radar screen. The player of the game defends a ship by launching missiles at approaching air targets. The game's complexity can be predetermined by changing speeds of incoming missiles and the tempo of operation (number and frequency of incoming missiles). Since the ship's detection range exceeds its weapon range, a player must decide the optimal time to launch a missile on the basis of target speed. The goal of the game is to effectively destroy incoming targets at the maximum range. Feedback is given to the player on target identity, successful launches, errors, target destruction, or a missile hit on the ship. The average range of intercept is the performance measure selected for analysis.

The game, which lasts $30 \mathrm{~min}$, is highly motivating, requiring sustained attention and timely decisions. The task was given five times on Monday for training purposes. The four administrations analyzed were on Tuesday at $2200 \mathrm{~h}$, Thursday at $0300 \mathrm{~h}$, and Friday at 0300 and $1230 \mathrm{~h}$.

Logical Reasoning Task. This task was devised by Baddeley (1968), was recently evaluated by Carter, Kennedy, and Bittner (1981), and has been used extensively in sustained operations research (e.g., Haslam, 1983; Thorne, Genser, Sing, \& Hegge, 1983). The task consists of the random presentation on the computer screen of one of 16 possible sentences (such as "A follows B") followed by a pair of letters (either "BA" or " $A B$ "). Subjects were instructed to enter a " 1 " on the terminal keyboard if the sentence was a true description of the letter pair or a " 2 "' if false (i.e., for the above example, "BA" is a true description of the grammatical relationship in the sentence "A follows B"; hence, " 1 ", would be entered on the keyboard). The subjects were urged to work accurately on as many sentences as possible in $3 \mathrm{~min}$. (Percent correct responses are reported in this paper.) Subjects were given the task seven times per CW episode. Two analyses were done: (1) Subjects with more than $60 \%$ correct at each episode (one $24-\mathrm{h}$ period) were analyzed $(\mathrm{N}=14)$, and (2) the total sample $(\mathrm{N}=$ 22) was analyzed.

Alpha-Numeric Visual Vigilance Task. In this task, single random alphabetical characters or numbers are presented on the screen at random time intervals ranging from 6 to $14 \mathrm{sec}$, with a mean interval of $10 \mathrm{sec}$. These numbers or characters remain on the screen for $10 \mathrm{msec}$. In our studies, subjects were instructed to press a handheld button with their thumb every time an A or a 3, the signal stimuli, appeared. An error of omission was declared when response to an $\mathrm{A}$ or a 3 was not made within $5.0 \mathrm{sec}$. This task lasted for $30 \mathrm{~min}$, during which 20 signal stimuli were randomly mixed with the other 160 numbers and letters presented. Percent correct responses was used as the measure. This task was given the first $.5 \mathrm{~h}$ of each 1-h session during both CW1 and CW2; thus, subjects completed this task 17 times per $\mathrm{CW}$ episode. The means of four time periods analyzed: morning (0900-1200 h), afternoon (1230-1630 h), evening (1715$2145 \mathrm{~h}$ ), and late evening (2215-0215 h).

Williams Auditory Word Memory Test. This shortterm memory task involves the presentation of 36 taperecorded lists of 15 words each. Three lists are presented each time the task is performed. Each word is announced, spelled, and then repeated. The subject is instructed to 


\begin{tabular}{|c|c|c|c|c|c|c|c|c|c|}
\hline & \multirow{2}{*}{$\begin{array}{c}\text { MONDAY } \\
\text { Training }\end{array}$} & \multicolumn{2}{|c|}{ TUESDAY } & \multicolumn{2}{|c|}{ WEDNESDAY } & \multicolumn{2}{|c|}{ THURSDAY } & \multicolumn{2}{|c|}{ FRIDAY } \\
\hline EXPT'L PHASE & & \multicolumn{2}{|c|}{ Baseline } & \multicolumn{2}{|c|}{ CW1 } & \multicolumn{2}{|c|}{ CW2 } & \multicolumn{2}{|c|}{ Recovery } \\
\hline TIME & WA WB & WA & WB & WA & WB & WA & WB & WA & WB \\
\hline $00 \cdot 01$ & & \multirow{8}{*}{\multicolumn{2}{|c|}{ SLEEP $\emptyset$}} & \multirow{5}{*}{\multicolumn{2}{|c|}{ SLEEP 1}} & $15 A$ & $15 B$ & I5A & $15 B$ \\
\hline & & & & & & $16 A$ & & $16 A$ & \\
\hline $01 \cdot 02$ & & & & & & & $16 \mathrm{~B}$ & & $16 B$ \\
\hline $02 \cdot 03$ & & & & & & $1 / 1 \mathrm{~A}$ & $17 B$ & I/A & $17 \mathrm{~B}$ \\
\hline $03-04$ & & & & & & & & \multicolumn{2}{|c|}{ ETS Task } \\
\hline $04-05$ & & & & & & \multirow{3}{*}{\multicolumn{2}{|c|}{ SLEEP 2}} & \multirow{10}{*}{\multicolumn{2}{|c|}{ SLEEP 3}} \\
\hline $05-06$ & & & & & & & & & \\
\hline $06 \cdot 07$ & \multirow{2}{*}{ TRAVEL } & & & & & & & & \\
\hline $07-08$ & & & -- & BREA & $\mathrm{AST}^{*}$ & --- & & & \\
\hline 08.09 & \multirow{2}{*}{ Forms } & TA & & TA & & TA & & & \\
\hline $08 \cdot 09$ & & & 18 & & $\mathrm{~TB}$ & & IB & & \\
\hline $09-10$ & \multirow{3}{*}{$\begin{array}{c}{\mathrm{Max} \mathrm{VO}_{2}}_{\text {Testing }}\end{array}$} & $2 A$ & 2B & $2 A$ & $2 B$ & $2 A$ & $2 B$ & & \\
\hline $10-11$ & & $3 \mathrm{~A}$ & & $3 A$ & & $3 A$ & & & \\
\hline & & $4 A$ & $3 B$ & $4 A$ & $3 B$ & $4 A$ & $3 B$ & & \\
\hline $11-12$ & $\mathrm{LUNCH}^{* *}$ & & 4B & & 48 & & $4 B$ & & \\
\hline $12-13$ & \multirow{2}{*}{$\begin{array}{l}\text { Computer } \\
\text { Task Trn }\end{array}$} & \multicolumn{6}{|c|}{----- LUNCH $----\frac{-}{5 \mathrm{~A}}$} & \multicolumn{2}{|c|}{ LUNCH } \\
\hline $13-14$ & & $6 A$ & $5 B$ & 64 & $5 B$ & $\mathrm{GA}$ & $5 B$ & & \\
\hline & \multirow{4}{*}{$\begin{array}{l}\text { ADG } \\
\text { Training } †\end{array}$} & & $6 B$ & & 68 & & $6 \mathrm{~B}$ & & \\
\hline $14-15$ & & $7 \mathrm{~A}$ & & $7 A$ & & $7 \mathrm{~A}$ & & & \\
\hline \multirow{2}{*}{$15-16$} & & & 7B & & $7 B$ & & $7 B$ & & \\
\hline & & $8 \mathrm{~A}$ & & $8 A$ & & $8 A$ & & & \\
\hline $16-17$ & DINNER & \multicolumn{6}{|c|}{----- SUPPER -----} & & \\
\hline $17 \cdot 18$ & \multirow{3}{*}{$\begin{array}{l}\text { Computer } \\
\text { Task'Trn }\end{array}$} & $9 A$ & & $9 A$ & & $9 A$ & & & \\
\hline & & & $9 \mathrm{~B}$ & & $9 \mathrm{~B}$ & & $9 B$ & & \\
\hline $18-19$ & & $10 \mathrm{~A}$ & $10 \mathrm{~B}$ & $10 \mathrm{~A}$ & $10 \mathrm{~B}$ & $10 \mathrm{~A}$ & 108 & & \\
\hline $19 \cdot 20$ & N-D Read. ${ }^{\dagger}$ & $11 \mathrm{~A}$ & & $11 \mathrm{~A}$ & & $11 \mathrm{~A}$ & & & \\
\hline $20-21$ & & $12 A$ & 11B & & $11 \mathrm{~B}$ & & $11 \mathrm{~B}$ & & \\
\hline $20-21$ & ADG & $12 \mathrm{~A}$ & $12 \mathrm{~B}$ & $12 \mathrm{~A}$ & $12 \mathrm{~B}$ & $12 \mathrm{~A}$ & $12 \mathrm{~B}$ & & \\
\hline $21 \cdot 22$ & & & - & SNA & *** & -1 & & & \\
\hline 22.23 & Word Mem & ETS & ask & & $13 B$ & & $13 \mathrm{~B}$ & & \\
\hline $22-23$ & vora iviem. & EEG & okup & $14 A$ & & $14 A$ & & & \\
\hline $23-24$ & SLEEP $\emptyset$ & SL & P 1 & T5A & 14B & $15 \mathrm{~A}$ & 14B & & \\
\hline
\end{tabular}

\section{CW $=$ Continuous Work}

*Includes time for attachment of ECG electrodes and rifle assembly task.

** Includes time for rifle assembly task.

$\uparrow$ Air Defense Game

†† Nelson Denny Reading Test

Figure 1. Protocol for sustained operations experiments $(A=$ first .5 h of session; exercise subjects on treadmill, nonexercise subjects seated in front of CRT; $B=$ second $.5 \mathrm{~h}$; all subjects worked at tasks described in text). 
write down the word as soon as he or she first hears it. The next word follows immediately after the second presentation of the previous word. As soon as the subject writes down the last word, the subject is given a recall sheet for writing down all remembered words in any order. Two minutes are allowed for each recall for each list (Williams, Gieseking, \& Lubin, 1966). Correct words recalled are calculated and expressed as percentages. In our studies, this test was given four times during each CW episode.

Educational Testing Service (ETS) Visual Memory Test. A kit of 72 factor-referenced, cognitive tests for 23 factors (mental aptitudes) is available from Eduational Testing Service (Ekstrom, French, Harman, \& Dermen, 1976). [These tests were developed in 1976 by Harman and associates under an Office of Naval Research (ONR) contract.] One factor of visual memory was selected to augment the Williams auditory memory test. The visual memory factor has three tests and represents the "ability to remember the configuration, location, and orientation of figural material" (Ekstrom et al., 1976, p. 109). The three tests examine the iconic sensory memory system (Atkinson \& Shiffrin, 1971, 1977; Sperling, 1960): (1) Shape Memory - The subject is asked to identify those irregular forms that have previously been seen in the same orientation on a study page (16 items). The subject is given $4 \mathrm{~min}$ for memorizing and $4 \mathrm{~min}$ for testing recall. (2) Building Memory-The subject is asked to indicate the location of a number of buildings seen on a previously studied map (12 items), again with $4 \mathrm{~min}$ for memorizing and 4 min for testing. (3) Map Memory-The subject is asked to identify sections of a map that have previously been presented on a study page. Three minutes are given for memorizing and $3 \mathrm{~min}$ for answering the 12 items. Each test is preceded by a short example section. The tests are suitable for Grades 6-16, and appear militarily relevant, particularly for reconnaissance troops (the subjects used in the present study). Subjects were given two different forms of the task, once at $2200 \mathrm{~h}$ Tuesday (second lab day for baseline data) and the other at $0230 \mathrm{~h}$ Friday (fifth lab day).

Four-Choice Serial Reaction Time Task (FourChoice). The Four-Choice task was developed by Wilkinson and Houghton (1975) and used in previous sleep-loss research (e.g., Glenville, Broughton, Wing, \& Wilkinson, 1978). In this task, subjects observed a blinking " +" (plus sign) in one of four quadrants of a computer monitor screen. Subjects were to press one of the four buttons on the terminal keyboard corresponding to the quadrants on the screen, that is, upper left, upper right, lower left, and lower right. The blinking " +" remained in a quadrant until one of the four buttons had been pressed, and then randomly reappeared in another quadrant or stayed in the same position. If none of the four buttons had been pressed in $2.5 \mathrm{sec}$, a bell sounded at 0.1 -sec intervals until a response had been made. This task lasted for $6 \mathrm{~min}$. Subjects were instructed to respond as accurately and quickly as possible. Percent correct responses was used to assess performance. The Four-Choice was given six times per $\mathrm{CW}$ episode.

Gates-Peardon Reading Exercise-Advanced. The Gates-Peardon Reading Exercises (Gates \& Peardon, 1963) consist of three short reading exercises, each followed by questions requiring reader response. The Advanced booklets were set to range from average sixthgraders to less able ninth-graders. Responses to the questions require the reader to utilize a range of reading skills while answering questions on three important types of reading: comprehending the main idea of a selection (Section About), reading to note and recall details (Remembering Details), and reading to understand precise directions (Following Directions). The selection of exercises was well within the reading abilities of the Marine Corps subjects, therefore avoiding reading level as an extraneous variable. The three types of reading skills examined (comprehension, remembering details, and following directions) are important to military communications. Previous studies have shown that comprehension and attention to details are degraded by sleep deprivation (Banderet, Stokes, Francesconi, Kowal, \& Naitoh, 1981; Johnson \& Naitoh, 1974). This reading task emphasized accuracy of responding rather than speed, which was emphasized in the other reading task (Miller Reading Efficiency Test, Miller, 1970). Subjects could refer to the reading passage while responding to questions. Subjects performed a Gates exercise six times per CW episode.

Miller Reading Efficiency Test. The test consists of five comparable standardized forms of a reading test designed to measure reading rate, comprehension, and efficiency. Each test is 5,000 words in length; lines are numbered for easy determination of reading rate. An answer sheet of 50 items is available with content organized so that the subject is tested only on material read. Test forms cover basic information, such as history, geography, culture, government, and people of some countries not usually encountered in school curriculum. All five forms were developed at comparable readability as measured by the Flesch Formula (Miller, 1970). In our study, subjects read for 2 min and then completed the test items pertaining to the material read. For their next reading, they continued from where they had finished during the last reading session. Number of lines completed was noted after each 2-min reading session. This task was given six times per $\mathrm{CW}$ episode. It has been used in previous circadian rhythm and cognitive performance research (Englund, 1979).

\section{Procedure}

For this study and others in the SUSOPS series, subjects were required to live, two at a time, in the laboratory for five days, Monday through Friday. Figure 1 depicts the data-collection protocol. Average ambient temperature $\left(21.1^{\circ} \mathrm{C}\right)$ and humidity $(50 \%)$ were maintained with air conditioning.

On Monday, subjects were given a graded maximum exercise test developed at the NHRC Physical Fitness 
Laboratory to assess $\mathrm{VO}_{2}$ max with simultaneous measurement of heart rate. During the remainder of Monday, subjects were familiarized with the study and trained in the various tasks. One member of each pair of subjects was assigned randomly to be the experimental subject. The other was treated as the control. Both subjects performed the same tasks at the same time throughout the experiment. In the first $.5 \mathrm{~h}$ of each $1-\mathrm{h}$ session, the experimental "exercise" subject performed the Alpha-Numeric Visual Vigilance Task while wearing full combat gear, carrying a pack and rifle, and walking on a treadmill. The gear worn and carried (boots, rifle, and field pack) by the experimental subjects weighed $27 \mathrm{~kg}$. The control, or "nonexercise," subject sat in a chair in front of a video monitor screen and performed the same Alpha-Numeric Visual Vigilance Task.

The experiment started at $0800 \mathrm{~h}$ Tuesday (see Figure 1). The first work segment, the baseline, consisted of 12 1-h blocks, and ended at $2115 \mathrm{~h}$. Experimental subjects walked on the treadmill for a total of $6 \mathrm{~h}$ during this 1 st day. Treadmill speed was determined by heart rate. The experimental subject's exercise heart rate was kept as near as possible to the rate determined from his individual exercise test to correspond to an energy expenditure equal to $30 \%$ of his $\mathrm{VO}_{2}$ max.

The first CW period (CW1) began Wednesday at $0800 \mathrm{~h}$ and ended at $0400 \mathrm{~h}$ Thursday $(20-\mathrm{h} \mathrm{CW})$. After the end of CW1, each subject was allowed a 3-h nap, from 0400 to $0700 \mathrm{~h}$ Thursday (Sleep 2 of Figure 1). Awakened from napping, subjects were given breakfast, and then at $0800 \mathrm{~h}$ the second $\mathrm{CW}$ episode, CW2, of 20-h duration began, ending at $0400 \mathrm{~h}$ Friday. After the end of CW2, subjects were allowed to sleep until $1200 \mathrm{~h}$ on Friday.

In Figure 1, the "sessions" with " $A$ " represent the 30-min period when the experimental subject walked on the treadmill and the control subject sat in front of a video monitor. Both subjects performed the Alpha-Numeric Visual Vigilance Task at this time. The sessions with " $B$ ", are the 30 -min periods when all subjects worked at other tasks.

\section{ANALYSIS}

Three-way analysis of variance (ANOVA, groups $\times$ days $\times$ sessions) for repeated measures was performed on each cognitive performance measure (BMDP, 2V, Dixon, 1983). When an $F$ ratio involving the comparisons of more than two means was significant, Tukey's HSD (Honestly Significant Differences) was computed (see Winer, 1971, p. 198). The analysis was performed to answer the following questions: (1) Did the physical workload affect performance (group difference)? (2) Did sleep loss affect performance (between-day difference)? (3) Did performance change as a function of time of day [session (each $1 \mathrm{~h}$ of the 24-h day) differences]? (4) What, if any, were the combined effects (interactions) between sleep loss, physical workload, and time-of-day variations? And (5) was the 3-h nap (0400-0700 h) effective for restoring performance?
Since the Alpha-Numeric Visual Vigilance Task was given 17 times on each of the $\mathrm{CW}$ days, the combined means of the morning (0800-1200 h), afternoon (1230$1630 \mathrm{~h})$, evening $(1715-2115 \mathrm{~h})$, and late night (2145$0245 \mathrm{~h}$ ) sessions were used in order to keep the number of repetitions smaller than the number of subjects. This action improved the stability of means in this small-N design. Two-way ANOVA (groups $\times$ days) was computed for the Educational Testing Service Visual Memory Test. Two forms of the test are available, and each was administered once. Two-way ANOVA (groups $\times$ days) was also computed for the Air Defense Game. There were four administrations of this test, one on each of 4 different days.

When more than $25 \%$ of a subject's data for a variable was missing, the subject was dropped from the analysis. For subjects with less than $25 \%$ missing data, a subject's 'grand mean was substituted for those sessions without data. Missing data occurred because the task (session performance) was dropped due to time constraints or because of computer hardware or software problems.

The Logical Reasoning Test, the most challenging cognitive task in our battery, was subject to guessing (chance equal to $50 \%$ correct). Two analyses were performed, one with subjects who had no sessions with guessing $(\mathrm{N}=$ 14 ) and one with all subjects $(N=22)$. No change in the significance of the results was found.

The baseline day was not analyzed, but was treated both as a training day and as a day on which most of any "learning curve" effects would have occurred; the CW days also involved five extra sessions (2145-0315 h) of the tasks that the baseline day did not have. It should be emphasized that CW1 occurred after $8 \mathrm{~h}$ of sleep, whereas CW2 occurred after a 3-h nap (0400-0700 h). Student $t$ tests of the between-episode (CW1/CW2) measures were used to examine the immediate effect of the 3-h early morning nap (0400-0700 h) upon performance.

Both the exercise (heart rate at $30 \% \mathrm{VO}_{2}$ max) and the sleep loss (5 h in $21 \mathrm{~h}$ of wakefulness) were of such moderate levels that neither should have had a predominant effect during the 1st day. The cumulative effects on performance, if any, from exercise and sleep loss should appear during the 2 nd day. Therefore, the interaction terms, particularly groups $\times$ days, were of special interest. The interference of any circadian rhythm effects in performance by these exercise and sleep-loss levels would also be apparent from significant interaction of sessions with either group or day, or both (group $x$ day $\times$ session). If the exercise group performed worse during the 2 nd $\mathrm{CW}$ day, especially during the later sessions, the cumulative fatigue due to physical workload would be indicated. If the controls were worse the 2 nd day, the beneficial effect of moderate exercise in counteracting sleep loss would be shown.

Recognizing the possible violations of the compound symmetry assumptions (pattern of constant variances in covariance matrix) in repeated-measures designs, we included the probabilities from the conservative GeisserGreenhouse (pGG) adjustments of the degrees of freedom 
(Geisser \& Greenhouse, 1958), along with the regular probabilities (pReg) as lower and upper bounds of significance in the tables. The probabilities from the Huynh and Feldt (1976) method were used in determining the significant findings for the repeated-measures effects in the text and tables (pHF $\leq .05$ ) because they reflect the covariance found in the repeated measures. This also avoids the Type II errors that are more likely to occur in the Geisser-Greenhouse method and the Type I errors that are found in using the probabilities from the regular degrees of freedom.

\section{RESULTS}

\section{Group Differences (Exercise Effects)}

The ETS "Building Memory" test was one of two cognitive performance measures indicating significant group differences $[F(1,20=7.11, p<.015]$. The control group located $10 \%$ more objects than the exercise group during both test administrations (Table 1). The Gates reading section called "Remembering Details" showed a trend toward a significant group difference $[\mathrm{F}(1,20=4.24$, $\mathrm{p}<.053$, with the control group averaging 7.1 questions correct out of 8 questions; the exercise group averaged 6.3 questions correct over the $2 \mathrm{CW}$ days (see Table 2 for main effects).

Analysis of the Alpha-Numeric Visual Vigilance (percent correct detections) Task indicated a significant interaction involving groups (groups $\times$ day $\times$ session) $(F=$ 3.41 , pHF <.036) (note: Huynh \& Feldt, 1976, adjusted degrees of freedom). Table 3 (also Figure 2) shows the significant difference in the linear trend of each group over the 2 days $[\mathrm{F}(1,20=4.96, \mathrm{p}<.04]$. The exercise group improved in performance ( $75.8 \%$ to $86.4 \%$ ) during CW1, whereas the control group's performance was essentially formance was essentially the same across the 1st day. During CW2, the exercise group showed the same slight improvement during the first half of the day as in CW1, declining significantly in percent correct detections only during the second half of CW2. The control group indicated significantly lower performance during CW2 (80\% CW1, CW2).

There was also a significant groups $\times$ day $\times$ session interaction for the Gates "Section About" measure ( $F=$ 3.67 , pHF < .004) (see Table 3 and Figure 3). Comparing similar sessions in CW1 and CW2, the control group performed less accurately during three $\mathrm{CW} 2$ sessions.

\section{Day Differences (Sleep-Deprivation Effects)}

Performance on the Alpha-Numeric Visual Vigilance Task indicated a significant day difference $[F(1,19)=$ $10.0, \mathrm{p}<.005]$. The mean percent correct detections was $80.9 \%$ during CW1, but only $70.6 \%$ during CW2, indicating a significantly lower performance on this task on the 2nd CW day. Additionally, performance on the ETS "Shape Memory" test showed $10 \%$ fewer correct responses $[F(1,20=10.18, p<.005]$ for both groups on the 2 nd test night ( $0300 \mathrm{~h}$ Friday). In contrast, subjects showed slight, although nonsignificant (pHF < .07), improvement over the experiment on the Air Defense Game.

\section{Session Differences (Time-of-Day Effects)}

Performance on both the Four-Choice $(F=3.65$, pHF $=.012)$ and the Logical Reasoning $(F=3.77$, pHF < .012) percent correct measures (Figure 4) showed significant session differences. Performance on the FourChoice task was significantly lower (79.5\%) during the last session (Session 17, 0230 h) than it was during all other administrations (85.2\%-87.7\%). Logical Reasoning was significantly better at $1900 \mathrm{~h}$ (Session 10) than at

Table 1

Means and Standard Deviations for ETS and Air Defense Game Average Range

\begin{tabular}{|c|c|c|c|c|c|c|c|c|}
\hline & & & & \multicolumn{5}{|c|}{ Day and Time of Administration } \\
\hline & & \multicolumn{2}{|c|}{ Group } & \multicolumn{2}{|c|}{ Prebaseline } & \multirow{2}{*}{$\frac{\text { End of CW } 1}{0300 \mathrm{~h}}$} & \multirow{2}{*}{$\frac{\text { End of CW2 }}{0300 \mathrm{~h}}$} & \multirow{2}{*}{$\frac{\text { Recovery }}{1200 \mathrm{~h}}$} \\
\hline & & Exercise & Control & $2030 \mathrm{~h}$ & $2100 \mathrm{~h}$ & & & \\
\hline \multicolumn{9}{|c|}{ ETS } \\
\hline \multirow[t]{2}{*}{ Shape Memory } & $\begin{array}{l}\text { Mean } \\
\text { SD }\end{array}$ & $\begin{array}{l}81.5 \\
11.3\end{array}$ & $\begin{array}{l}82.0 \\
11.1\end{array}$ & & $\begin{array}{r}87.0 \\
8.9\end{array}$ & & $\begin{array}{l}76.5 \\
12.6\end{array}$ & \\
\hline & & & $(\mathrm{F}=1$ & $10.2, p=$ & $=.005)$ & & & \\
\hline Map Memory & $\begin{array}{l}\text { Mean } \\
\text { SD }\end{array}$ & $\begin{array}{l}76.2 \\
17.8\end{array}$ & $\begin{array}{l}73.3 \\
16.3\end{array}$ & & $\begin{array}{l}73.3 \\
18.2\end{array}$ & & $\begin{array}{l}76.2 \\
15.5\end{array}$ & \\
\hline \multirow[t]{2}{*}{ Building Memory } & $\begin{array}{l}\text { Mean } \\
\text { SD }\end{array}$ & $\begin{array}{r}93.4 \\
8.1\end{array}$ & $\begin{array}{l}85.1 \\
12.1\end{array}$ & & $\begin{array}{l}87.7 \\
10.5\end{array}$ & & $\begin{array}{l}90.0 \\
10.8\end{array}$ & \\
\hline \multirow{2}{*}{\multicolumn{5}{|c|}{$\begin{array}{c}(F=7.11, p=.015) \\
\text { Air Defense Game }\end{array}$}} & & & & \\
\hline & & & Air I & Defense C & Game & & & \\
\hline $\begin{array}{l}\text { Average Range } \\
\text { at Intercept }\end{array}$ & $\begin{array}{l}\text { Mean } \\
\text { SD }\end{array}$ & $\begin{array}{r}17.0 \\
1.2\end{array}$ & $\begin{array}{r}17.0 \\
1.2\end{array}$ & $\begin{array}{r}16.7 \\
1.1\end{array}$ & & $\begin{array}{r}16.8 \\
1.4\end{array}$ & $\begin{array}{r}17.2 \\
1.2\end{array}$ & $\begin{array}{r}17.3 \\
1.0\end{array}$ \\
\hline \multicolumn{9}{|c|}{$[F$ Admin $=3.08, \mathrm{df}=3 ; \mathrm{p}$ reg $=.04 ; \mathrm{p} \mathrm{GG}=.12 ; \mathrm{p}$ HF $=.07$ (n.s.) $]$} \\
\hline
\end{tabular}


either $2240 \mathrm{~h}$ or $0215 \mathrm{~h}$. Morning $(1000 \mathrm{~h})$ and afternoon $(1530 \mathrm{~h})$ performance on this task was not significantly different from that on any other session.

There was a statistically significant day $\times$ session interaction $(F=3.90$, pHF $<.013)$ found for Word Memory percent recall, with a significant difference in linear trend across sessions on the 2 days $(F=8.85, p<.008)(\mathrm{Ta}-$ ble 3, Figure 5). There was a significant linear decrease in percent recall during CW1 (1000-0245 h). Performance during CW2 followed a more quadratic profile, with lowest recall during Session $1(1000 \mathrm{~h})$ and higher recall during the middle of the day and evening, with a slight drop again by $0245 \mathrm{~h}$ (Session 17). Memory for words was worse for the last session of CW1 and the first session of CW2 than it was for all other administrations.

The performance profile for the "Section About" section of the Gates Reading Test had significantly different session means $[\mathrm{F}(5,100)=4.43, \mathrm{pHF}<.001]$. Analysis of performance for the "Following Directions" section of the Gates showed significant session differences $(F=$ 3.76 , $\mathrm{pHF}<.004)$. Both of these areas of reading indicated that subjects performed worse at Session 9 (1800 h). Peak performance occurred at different times for these two tasks (Section About, at $2400 \mathrm{~h}$; Following Directions, at $1400 \mathrm{~h}$ ). There was also a significant interaction for Following Directions (days $\times$ sessions, $F=3.23$, pHF $<.013$; Figure 6). A significant linear decline appeared during CW2, whereas CW1 showed the higher order trends (linear trends) $[\mathrm{F}(1,20=6.72, \mathrm{p}<.02]$.

\section{Nap-Inertia Effects}

Performance differences were computed (Student $t$ test) for several tasks just before and after the 3-h nap. The amount of time between the last time during CW1 that a subject performed a particular cognitive task and the first time the subject performed the same task in CW2 ranged from 6 to $8 \mathrm{~h}$. Computations for all tasks indicated no significant differences. Student $t$ tests that compared the combined morning sessions of each $\mathrm{CW}$ day indicated no immediate recovery with nap following $21 \mathrm{~h}$ of wakefulness.

\section{Nonsignificant Measure}

There were no significant group, day, or session maineffect differences or interactions found for performance on the Miller's RET.

\section{DISCUSSION}

In the design of this study, an attempt was made to cover a wide range of cognitive abilities. The results indicated that the various tasks were differentially affected by sleep loss, physical work, and time of day. The results also indicated that taking a 3-h nap between successive 21-h sustained operations appeared to have no immediate effect upon performance of cognitive tasks (at least during the first session of CW2). This same conclusions had been

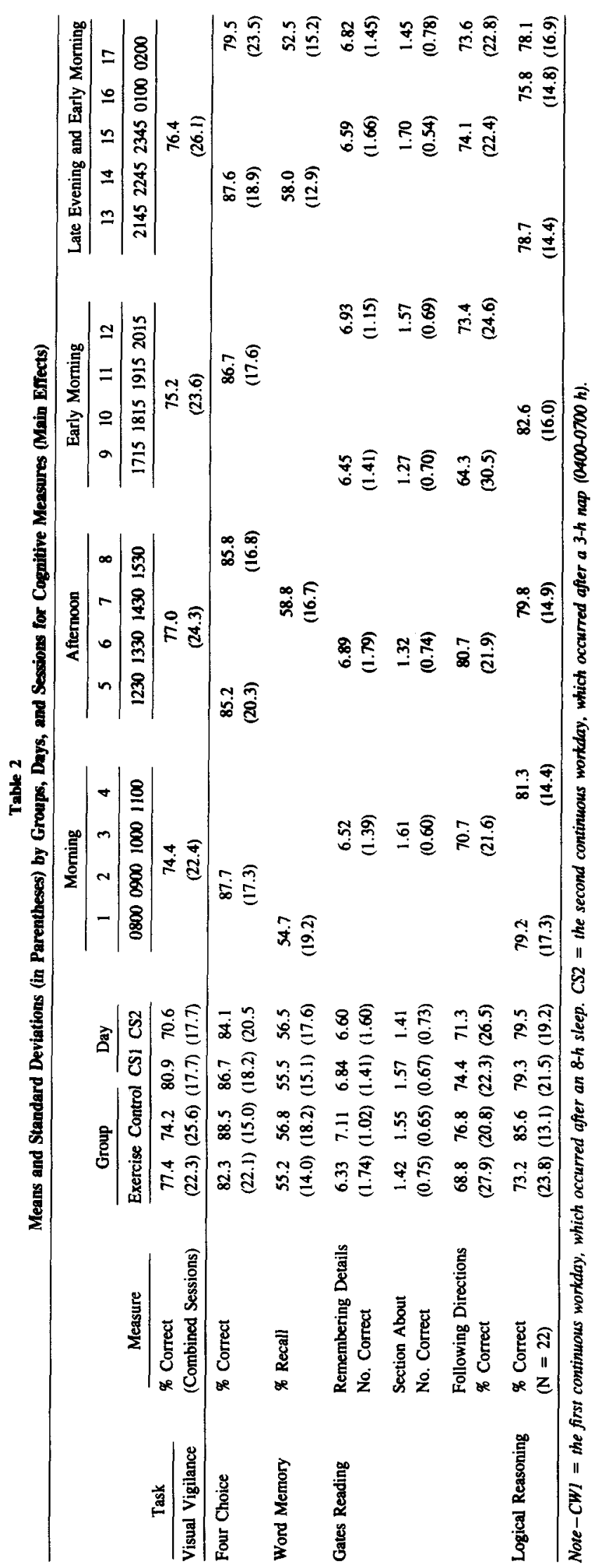


Table 3

Means and Standard Deviations for Variables with Significant Interactions

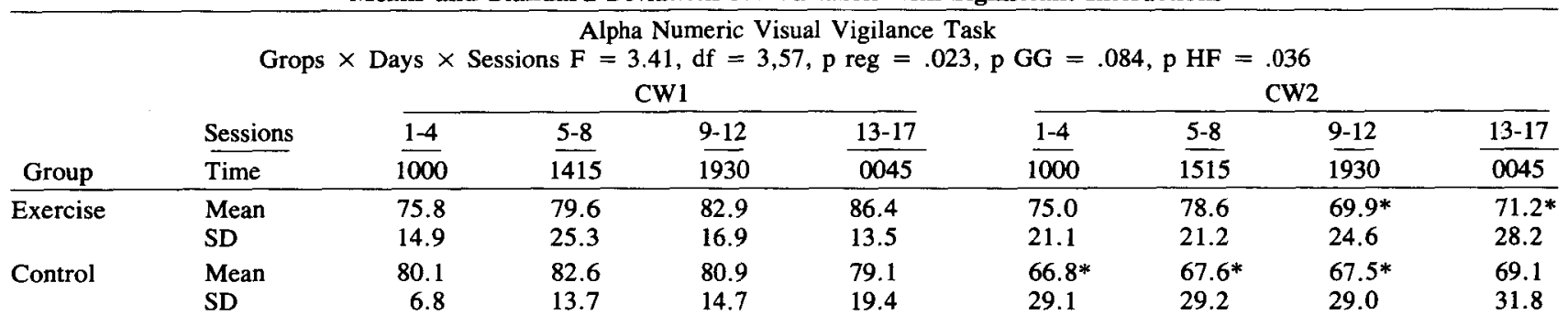

Word Memory (Percent Correct Recall)

Days $\times$ Sessions $\mathrm{F}=4.48, \mathrm{df}=3,60, \mathrm{p}$ reg $=.007, \mathrm{p} \mathrm{GG}=.047, \mathrm{p} \mathrm{HF}=.007$

\begin{tabular}{|c|c|c|c|c|c|c|c|c|}
\hline \multirow[b]{2}{*}{ Session } & \multicolumn{4}{|c|}{ CW1 } & \multicolumn{4}{|c|}{$\mathrm{CW} 2$} \\
\hline & 1 & 7 & 13 & 17 & 1 & 7 & 13 & 17 \\
\hline Time & $\overline{0855}$ & $\overline{1525}$ & 2240 & 0255 & $\overline{0855}$ & $\overline{1525}$ & $\overrightarrow{2240}$ & 0255 \\
\hline $\begin{array}{l}\text { Mean } \\
\text { SD }\end{array}$ & $\begin{array}{l}60.0 \\
14.9\end{array}$ & $\begin{array}{l}58.3 \\
15.0\end{array}$ & $\begin{array}{l}55.8 \\
12.0\end{array}$ & $\begin{array}{l}49.1^{\text {** }} \\
16.4^{2}\end{array}$ & $\begin{array}{l}48.4^{*} \\
22.2\end{array}$ & $\begin{array}{l}59.2 \\
18.0\end{array}$ & $\begin{array}{l}60.5 \\
13.5\end{array}$ & $\begin{array}{l}58.1 \\
12.7\end{array}$ \\
\hline
\end{tabular}

Gates Reading "Section About" Section

\begin{tabular}{|c|c|c|c|c|c|c|c|}
\hline & $\begin{array}{l}\text { Groups } \\
\text { Session } \\
\end{array}$ & $\begin{array}{c}\text { ys } \times \text { Ses } \\
3 \\
\end{array}$ & $\begin{array}{c}3.67 \\
6 \\
\end{array}$ & $\begin{array}{c}\text { p reg } \\
9 \\
\end{array}$ & $\begin{array}{c}\mathrm{GG}= \\
12 \\
\end{array}$ & $\begin{array}{c}=.004 \\
15\end{array}$ & 17 \\
\hline Exercise & $\begin{array}{l}\text { CW1 M(SD) } \\
\text { CW2 M(SD) }\end{array}$ & $\begin{array}{l}1.9(.3) \\
1.4(.7)\end{array}$ & $\begin{array}{l}1.5(.8) \\
1.3(.8)\end{array}$ & $\begin{array}{l}1.1(.5) \\
1.3(.8)\end{array}$ & $\begin{array}{l}1.5(.7) \\
1.4(.7)\end{array}$ & $\begin{array}{l}1.5(.5) \\
1.7(.5)\end{array}$ & $\begin{array}{l}1.4(.5) \\
1.2(.9)\end{array}$ \\
\hline Control & $\begin{array}{l}\text { CW1 M(SD) } \\
\text { CW2 M(SD) }\end{array}$ & $\begin{array}{l}1.7(.5) \\
1.5(.5)\end{array}$ & $\begin{array}{l}1.2(.6) \\
1.4(.7)\end{array}$ & $\begin{array}{l}1.6(.7) \\
1.1 *(.7)\end{array}$ & $\begin{array}{l}2.0(.0) \\
1.4 *(.7)\end{array}$ & $\begin{array}{l}2.0(.0) \\
1.5 *(.5)\end{array}$ & $\begin{array}{l}1.4(.5) \\
1.9(.3)\end{array}$ \\
\hline
\end{tabular}

Gates Reading "Following Directions" Section

Days $\times$ Sessions $F=3.23, \mathrm{df}=5,100, \mathrm{p}$ reg $=.009, \mathrm{p} \mathrm{GG}=.087, \mathrm{p} \mathrm{HF}=.013$

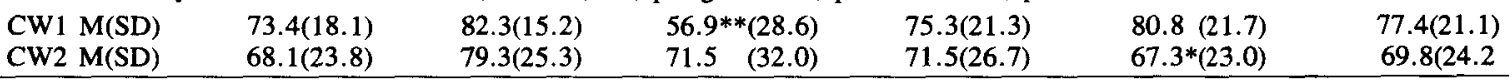

Note $-C W I=$ the first continuous workday which followed an 8-h sleep; $C W 2=$ the second continuous workday which followed a 3-h nap $(0400-0700 \mathrm{~h}) ;$ Time $=$ midpoint time of administration of task. $p$ reg $=$ regular df; $p$ GG $=$ Geiser-Greenhouse adjusted df; $p$ HF $=$ Huynh Feldt adjusted df. $\quad *=$ Session Mean significantly $(p<.01)$ lower CW2 than same session CWl (Tukey's HSD). $\quad * *=$ Session Mean significantly $(p<.01)$ higher CW2 than same session CW1 (Tukey's HSD).

reached previously for psychomotor, but not necessarily for strength, measures (Englund et al., 1983).

The effects of sustained exercise were tested by determining the difference between the two groups (exercise and nonexercise). Two of the eight tasks indicated a possible work effect. The nonexercise group clearly showed a $10 \%$ advantage when required to locate buildings previously seen on a map. This advantage, however, was shown during both administrations of this test when the analysis was performed for percent correct responses. No exercise effect (or group difference) was found for total number of correct responses rather than percent. In this case, the nonexercise group completed fewer questions (left more blank) but had the same number correct as the controls. Since there were only two forms of the test, any effect of physical work would have to have also appeared during the second administration (CW2). It did not. No real effect was produced by the physical work upon map memory (iconic memory used to store visual impressions).

Throughout the experiment, the nonexercise group was able to remember the details of a recently read passage slightly better than the exercise group. A related finding was reported during two 38-h successive sustained oper- ations (in laboratory setting) separated by a 34-h rest period (Bandaret et al., 1981, p. 14). Subjects in a Fire Direction Center simulation began to ignore or miss important spoken message details during the second episode, which resulted in endangering friendly troops.

Sleep deprivation affected the performance of all subjects on some tasks. Their ability to correctly detect specific targets in the Alpha-Numeric Visual Vigilance Task decreased by $10 \%$ on the $2 \mathrm{nd} \mathrm{CW}$ day. Their ability to correctly identify objects of different shapes (ETS shape memory) also decreased by the same percentage. Exercise may have delayed the decrement in alphanumeric target detection for as much as $\mathbf{8 ~ h}$ into the $2 \mathrm{nd} \mathrm{CW}$ day. This finding indicates that sustained sedentary CRT monitoring may suffer by as much as $12 \%$ after just 1 day without some physical exercise between tasks. Thus, moderate exercise while attending to a CRT may extend target-detection performance levels $8 \mathrm{~h}$ and may limit the performance decrement when it occurs (in this case, 6\%).

A sleep-deprivation effect was found for another component of the map memory test (ETS). Memory for irregular shapes had decreased $10 \%$ by CW2. Whereas exercise (at $30 \% \quad \mathrm{VO}_{2}$ max) had no effect upon iconic 


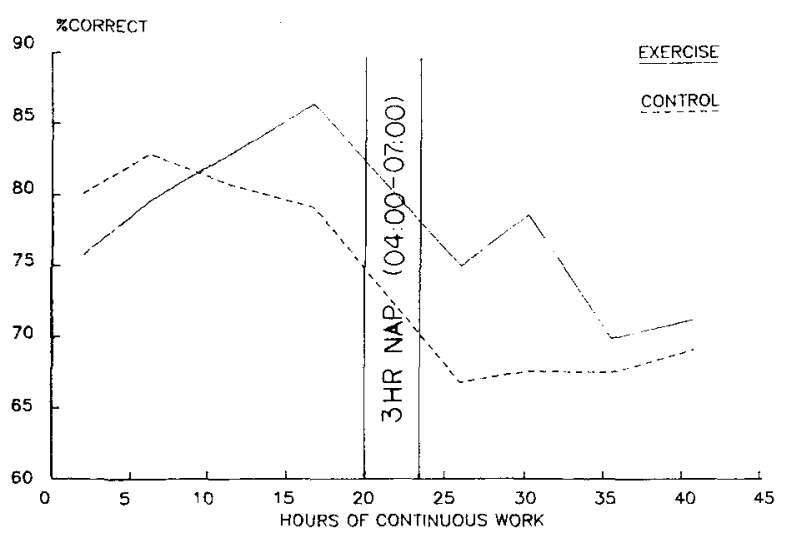

Figure 2. Alpha-Numeric Visual Vigilance Task, group means over 2 continuous workdays.

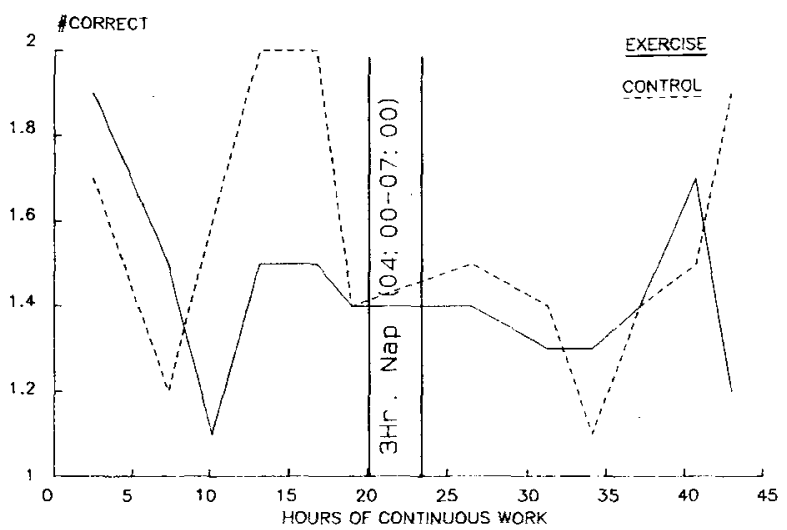

Figure 3. Gates Reading "Section About" number correct, group means over 2 continuous workdays.

memory, apparently sleep loss did. This may be an addition to the memory and sleep-loss data. Williams et al. (1966) found that learning in sleep-deprived subjects was less efficient when the new material was recalled after a night of rest than was learning under normal conditions. Compared with rested subjects, however, learning on one day and recalling on the next was not affected by intervening sleep loss. Subjects were required to recognize material immediately after learning and under the same conditions. Further support for the influence of sleep loss on memory was found in the declines in word memory performance during CW1 and during the early part of CW2. This effect was confounded by time-of-day and nap-inertia effects. The 3-h nap may have enhanced word memory performance later in the 2nd day (CW2), although improvement was not seen immediately after the nap, perhaps because of nap inertia.

There were no significant two-way interactions for groups $\times$ days for any of the measures, which indicates that the repeated moderate exercise combined with the sleep loss did not have a direct impact on the cognitive functions measured in this study. Most other researchers have not found performance decrements from exercise with sleep loss. Webb and Agnew (1973) found no detri-

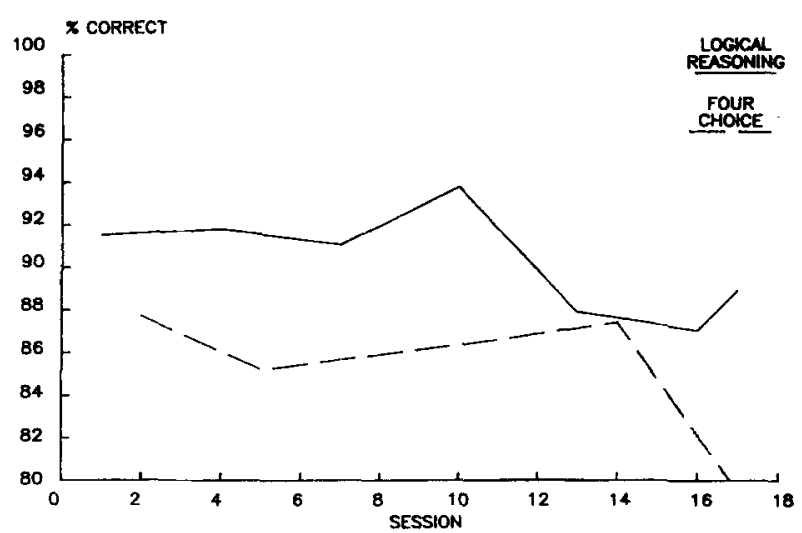

Figure 4. Logical-Reasoning and Four-Choice percentage correct over sessions.

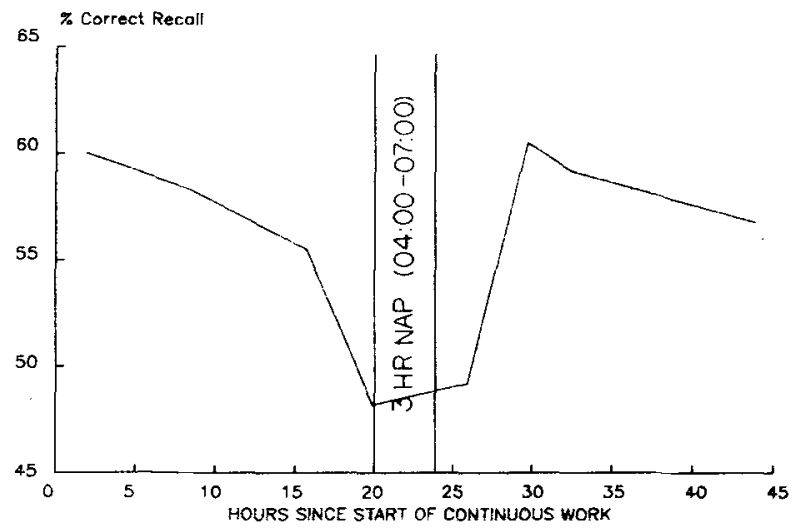

Figure 5. Word Memory percentage recall, session means over 2 continuous workdays.

mental effects for exercise (bicycle ergometer for $15 \mathrm{~min}$ every $2 \mathrm{~h}$ ) in 2 nights of sleep loss $(5.5 \mathrm{~h}$ of sleep each night), but did find an improvement in simple arithmetic addition with exercise. They found that sleep loss decreased performance in memory, complex addition, and
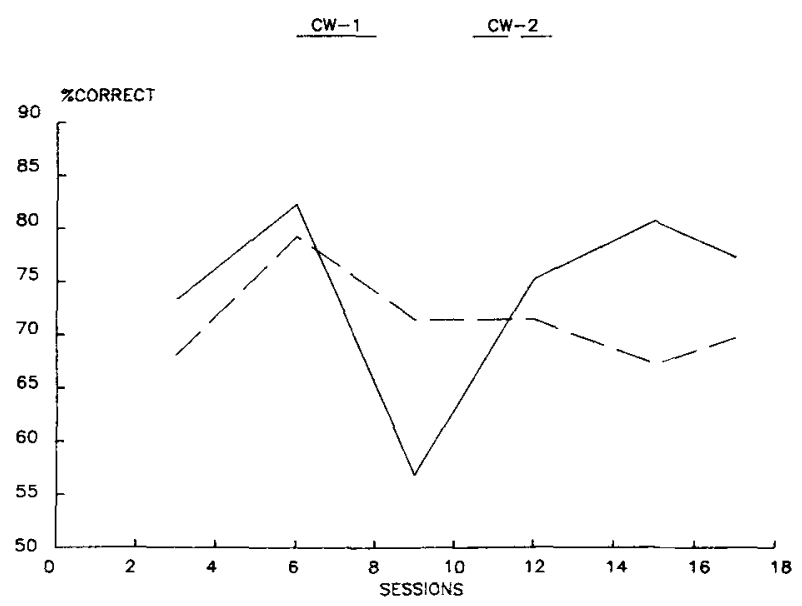

Figure 6. Gate's Reading "Following Directions," Days by Sessions percentage corrrect. 
auditory vigilance. Angus, Heslegrave, and Myles (in press) using a similar exercise protocol as the present study (treadmill walking at $25 \%-30 \%$ of maximal aerobic capacity) over a longer period of time $(64 \mathrm{~h})$ found sleep loss, not exercise, to be associated with decreased performance in auditory vigilance, Four-Choice, and Logical Reasoning. Lubin, Hord, Tracy, and Johnson (1976) compared the performance of exercise (riding bicycle ergometer at 5 miles/h for $1 \mathrm{~h}$ out of every $4 \mathrm{~h}$; a $50 \%$ increase in resting heart rate) with no sleep over $40 \mathrm{~h}$, and sleep and bed-rest groups. They found decreased performance in word memory and simple addition for the exercise group. The sleep and bed-rest groups had more rest, indicating that intermittent exercise with no nap or rest over $40 \mathrm{~h}$ produced some decreases in cognitive functioning.

Performance on the Air Defense Game (the task considered the most interesting by our subjects) may have improved slightly over the course of the $2 \mathrm{CW}$ days. This showing could indicate that performance on interesting/exciting tasks can continue to show learning trends up to 2 days in spite of numerous previous practice trials and moderate sleep loss. In a previous report (Englund et al., 1983), a similar improvement was noted in a rifleassembly task in which subjects competed for best times. Thus, competition and interest, each a motivating factor, influenced both psychomotor and cognitive task performance during sustained operations.

No decrements were found in the 2-min Miller Reading Efficiency Task. The RET performance time, although set as a message reading task, may have been too limited to show effects. Short-duration or interesting and motivating tasks requiring a brief energy burst often show no performance changes over time (Alluisi \& Chiles, 1967; Wilkinson, 1964). Similarly, Haslam (1983) recently reported that increased willingness to perform overcame performance decrements arising from sleep deprivation. The RET passages are highly interesting to subjects.

Time of day was again implicated in sustained operations performance change (Englund, 1979; Englund et al., 1983), although, in some cases, sleep loss and exercise contributed to the effect. The ability to make rapid choices decreased by $7 \%$ in the early morning hours. A similar finding was reported in a field study by Angus, Pearce, and Olsen (1981). A similar, but larger, drop was noted in the ability to think logically, after peak performance in the evening hours. Since no interactions were found, these changes were probably attributable to circadian effects. Alluisi and Chiles (1967) reported that the addition of simultaneously performed tasks produced sufficient stress on subjects to accentuate reduced performance rhythm. Information and motivation were shown to overcome or modify that same rhythm.

Reading a message and determining what it means, and then following the directions, each presented significant time-of-day profiles. However, both of these components of reading were also influenced by other than time-of-day factors. Exercise, sleep loss, and time of day combined to decrease the ability to extract the central meaning from a message at the end of the 2nd day. Sleep loss interacted most with time of day to flatten the rhythm effect for following directions on the 2 nd $\mathrm{CW}$ day. Previously, Englund (1979) reported that reading comprehension, speed, and efficiency indicated different time-of-day profiles. Interaction effects of sleep loss or physical work were not measured.

The performance similarities before and after napping may be accounted for by both after-nap sleep inertia (Naitoh \& Townsend, 1970) and circadian influences (Folkard \& Monk, 1980) combined with fatigue. Sleep inertia can last for 1-2 h or more (Taub, 1979; Wilkinson \& Stretton, 1971). The circadian low in oral temperature and task performance has been found during the early morning hours (Englund, 1979; Englund et al., 1983), the time when the 3-h nap was. Whatever value the 3-h nap may have had, it was not enough to overcome the effects of sleep inertia and circadian influences. The combined effects of nap inertia, time of day, and length of previous work schedule are suggested as the basis for lack of improvement in performance after nap.

The results from this study indicate that moderate exercise does not combine with sleep loss to further decrease cognitive performance. Variability at different times of the day, however, appeared to have a greater impact on cognitive abilities than the sleep loss or exercise levels.

\section{REFERENCES}

Alluisi, E. A., \& CHIles, W. D. (1967). Sustained performance, workrest scheduling and diurnal rhythms in man. Acta Psychologica, 27, 436-442.

Angus, R. G., Heslegrave, R. J., \& Myles, W. S. (in press). Effects of 64 hours of sleep deprivation, with and without chronic physical exercise, on mood and performance. Psychophysiology.

Angus, R. G., Pearce, D. G., \& Olsen, L. (1981, April). Performance on a multiple-choice reaction time test during a period of sustained physical exercise. In M. Radomski \& M. Defayolle (Eds.), Fastball: Physiological, psychological and biochemical aspects of a daily sustained submaximal exercise. Canada: Department of National Defence.

Atkinson, R. C., \& Shiffrin, R. M. (1971). The control of short-term memory. Scientific American, 224(2), 82-90.

Atkinson, R. C., \& Shiffrin, R. M. (1977). Human memory: A proposed system and its control processes. In G. H. Bower (Ed.), Human memory: Basic processes. New York: Academic Press.

BADDELEY, A. D. (1968). A 3 min reasoning test based on grammatical transformation. Psychonomic Science, 10, 341-342.

Bandaret, L. E., Stokes, J. W., Francesconi, R., Kowal, D. M., \& NAITOH, P. (1981). Artillery teams in simulated sustained combat: Performance and other measures. In NIOSH Proceedings, The 24-hr workday (Pub. No. 81-127, pp. 581-604). Cincinnati, OH: U.S. Department of Health and Human Services.

Brown, J. I. (1966). The Nelson-Denny Reading Test (rev. ed.). Boston: Houghton-Mifflin.

Carter, R. C., Kennedy, R. S., \& Bittner, A. C., JR. (1981). Grammatical reasoning: A stable performance yardstick. Human Factors, 23, 587-591.

DiXoN, W. J. (Ed.). (1983). BMDP statistical software. Berkeley: University of California Press.

Ekstrom, R. B., French, J. W., Harman, H. H., Dermen, D. (1976). Kit of factor-referenced cognitive tests. Princeton, NJ: Educational Testing Service. 
ENGLUND, C. E. (1979). Human chronopsychology: An autorhythmometric study of circadian periodicity in learning, mood and task performance. Unpublished doctoral dissertation, United States International University, San Diego.

Englund, C. E., Naitoh, P., Ryman, D. H., \& Hodgdon, J. A. (1983). Moderate physical work effects on performance and mood during sustained operations (SUSOPS) (NHRC Rep. No. TR 83-6). San Diego, CA: Naval Health Research Center.

FolKARD, S., \& MoNK, T. H. (1980). Circadian rhythms in human memory. British Journal of Psychology, 71, 295-307.

Gates, A., \& Peardon, C. C. (1963). Reading exercises. New York: Teachers College Press.

Geisser, S., \& GrEenHouse, S. W. (1958). An extension of Box's results on the use of the F-distribution in multivariate analysis. Annals of Mathematical Statistics, 29, 885-891.

Glenville, M., Broughton, R., Wing, A. B., \& Wilkinson, R. T. (1978). Effects of sleep deprivation on a short duration performance measure compared to the Wilkinson auditory vigilance test. Sleep, 1, 169-176.

Greitzer, F. L., Hershman, R. L., \& Kelly, R. T. (1981). The air defense game: A microcomputer program for research in human performance. Behavior Research Methods \& Instrumentation, 13, 57-59.

HASLAM, D. R. (1983). The incentive effect and sleep deprivation. Sleep, 6, 362-368.

HuYNH, H., \& FELDT, L. S. (1976). Estimation of the Box correction for degrees of freedom from sample data in the randomized block and split-plot designs. Journal of Educational Statistics, 1, 69-82.

JoHNSON, L. C., \& NAITOH, P. (1974). The operational consequences of sleep deprivation and sleep deficit (AGARD Rep. No. AG-193). London: North Atlantic Treaty Organization.

Lubin, A., Hord, D., Tracy, M. L., \& Johnson, L. C. (1976). Effects of exercise, bedrest and napping on performance decrement during 40 hours. Psychophysiology, 13, 334-339.

MiLLER, L. L. (1970). Reading efficiency tests. Laramie, WY: Developmental Reading Distributors.

NaITOH, P. (1981). Circadian cycles and restorative power of naps. In L. C. Johnson, D. I. Tepas, W. P. Colquhoun, \& M. J. Colligan (Eds.), Biological rhythms, sleep and shift work (pp. 553-580). New York: Spectrum.

NaitoH, P., ENGlund, C. E., \& Ryman, D. H.(1982). Restorative power of naps in designing continuous work schedules (NHRC Tech. Rep. No. 82-25). San Diego, CA: Naval Health Research Center. [Also in Journal of Human Ergology (Suppl.), 11, 1982, 259-278]

Naitoh, P., Englund, C. E., \& Ryman, D. H. (1983, 2-4 May). Ex- tending human effectiveness during sustained operations through sleep management. Proceedings of the 24th DRG Seminar on The Human as Limiting Element in Military Systems [Vol. 1, pp. 113-138, DS/A/DR(83)170]. Toronto: Defence Research Group.

NAITOH, P., \& ToWNSEND, R. E. (1970). The role of sleep deprivation research in human factors. Human Factors, 12, 575-585.

RaDomsio, M., \& Defayolle, M. (Eds.). (1981, April). Fastball: Physiological, psychological and biochemical aspects of a daily sustained submaximal exercise (Franco-Canadian Accord Theme 8, II). Toronto: Defence Research Group.

Ryman, D. H., Naitoh, P., \& Englund, C. E. (1984). Minicomputeradministered tasks in the study of effects of sustained work on human performance. Behavior Research Methods, Instruments, \& Computers, 16, 256-261.

SPERLING, G. (1960). The information available in brief visual presentation. Psychological Monographs, 74(11, Whole No. 498).

Spinweber, C. L., Johnson, L. C. (1983, 2-4 May). Psychopharmacological techniques for optimizing human performance. Proceedings of the 24th DRG Seminar on The Human as a Limiting Element in Military Systems [Vol. 1, pp. 139-160, DS/A/DR(83)170]. Toronto: Defence Research Group.

TAUB, J. M. (1979). Effects of habitual variation in napping on psychomotor performance, memory and subjective states. International Journal of Neuroscience, 9, 97-112.

Thorne, D., Genser, S., Sing, H., \& HegGe, F. (1983, 2-4 May). Plumbing human performance limits during 72 hours of high task load. Proceedings of the 24th DRG Seminar on The Human as a Limiting Element in Military Systems proof [Vol. 1, DS/A/DR(83)170]. Toronto, Canada.

WEBB, W. B., \& AGNEW, H. W. (1973). Effects of performance on high and low energy expenditure during sleep deprivation. Perceptual and Motor Skills, 37, 511-514.

WiLkinson, R. T. (1964). Effect of up to 60 hours of sleep deprivation on different types of work. Ergonomics, 7, 175-186.

Wilkinson, R. T., \& Houghton, D. (1975). Portable four-choice reaction time test with magnetic tape memory. Behavior Research Methods \& Instrumentation, 7, 441-446.

WiLkinson, R. T., \& STRETton, M. (1971). Performance after awakening at different times of night. Psychomotor Science, 23, 283-285.

Williams, H. L., Gieseking, C. F., \& LubiN, A. (1966). Some effects of sleep loss on memory. Perceptual and Motor Skills, 23, 1287-1293.

WINER, B. J. (1971). Statistical principles in experimental design (2nd ed.). San Francisco: McGraw-Hill. 